\title{
Extremely high-dose insulin requirement in a diabetic patient with COVID-19: a case report
}

\author{
François R. Jornayvaz', Benjamin Assouline², Jérôme Pugin² and Karim Gariani ${ }^{* *}$
}

\begin{abstract}
Background: Detailed description of hyperglycemia management in diabetic patients infected with SARS-CoV-2 remain limited, although patients with diabetes show higher complication and mortality rate than patients without diabetes. Transient non-severe increased insulin requirement in patients hospitalized for medical conditions such as sepsis or myocardial infarction is a well-known phenomenon. However, extremely high-dose insulin requirement remains a very rarely reported entity. Here, we report the case of an extreme and transitory insulin requirement episode in a type 2 diabetic patient presenting an acute respiratory distress syndrome caused by SARS-CoV-2.
\end{abstract}

Case presentation: A 57-year-old man resident in Geneva, Switzerland, previously known for type 2 diabetes for 3 years was admitted for an aggravation of his dyspnea. His type 2 diabetes was treated only with metformin and his latest Hb1Ac was 6.1\%. Chest CT SCAN showed a bilateral multilobar ground-glass opacification. Twenty-four hours after his admission he presented a worsening of dyspnea and severe hypoxemia requiring a transfer to the intensive care unit rapidly followed by oro-tracheal intubation for mechanical ventilation support. A bronchoalveolar lavage was performed and test of SARS-CoV-2 by RT-qPCR assay was positive. At day 3 , he presented a rapidly progressive insulin requirement at a rate of up to 50 units/hour intravenous insulin aspart. Despite the high insulin doses, he maintained an elevated plasma glucose level at $270 \mathrm{mg} / \mathrm{dL}$ on average. His extremely high-dose insulin requirement "resolved" at day 9 , and the insulin infusion rate was rapidly reduced.

Conclusions: This case may reflect a specific and profound impact of SARS-CoV-2 on metabolic homeostasis, in particular in diabetic patients that appear more prone to complications of COVID-19 infection. Yet, the mechanisms behind this remain to be elucidated. The optimal management of hyperglycemia of diabetic patients infected with SARS-CoV-2 has yet not be defined, however insulin remain the mainstay of treatment approach. Report of extreme dysregulation of chronic conditions such as diabetes in patients with COVID-19 may help clinicians to better take care of patients during the pandemic of SARS-CoV-2.

To the best of our knowledge this is the first description of extremely high-dose insulin requirement in patient with COVID-19.

Keywords: COVID-19, Insulin resistance, Type 2 diabetes, Case report

\footnotetext{
*Correspondence: karim.gariani@hcuge.ch

'Division of Endocrinology, Diabetes, Nutrition and Therapeutic patient education, Geneva University Hospitals, Geneva, Switzerland

Full list of author information is available at the end of the article
}

(c) The Author(s). 2020 Open Access This article is licensed under a Creative Commons Attribution 4.0 International License, which permits use, sharing, adaptation, distribution and reproduction in any medium or format, as long as you give appropriate credit to the original author(s) and the source, provide a link to the Creative Commons licence, and indicate if changes were made. The images or other third party material in this article are included in the article's Creative Commons licence, unless indicated otherwise in a credit line to the material. If material is not included in the article's Creative Commons licence and your intended use is not permitted by statutory regulation or exceeds the permitted use, you will need to obtain permission directly from the copyright holder. To view a copy of this licence, visit http://creativecommons.org/licenses/by/4.0/ The Creative Commons Public Domain Dedication waiver (http://creativecommons.org/publicdomain/zero/1.0/) applies to the data made available in this article, unless otherwise stated in a credit line to the data. 


\section{Background}

Since December 2019, an outbreak of coronavirus disease, officially named by the World Health Organization as COVID-19, appeared in Wuhan, Hubei Province, China. Diabetic patients infected with SARS-CoV-2 appear more prone to require hospitalization and admission to intensive care unit.

Transient non-severe increased insulin requirement in patients hospitalized for various medical conditions such as sepsis or myocardial infarction is a well-known phenomenon with insulin doses usually not exceeding 5-10 Units/hours [1]. However, extremely high-dose insulin requirement remains a very rare reported entity. Here, we report the case of an extreme and transitory high-dose insulin requirement episode in a diabetic patient presenting an acute respiratory distress syndrome (ARDS) caused by SARS-CoV-2.

\section{Case presentation}

A 57-year-old man previously known for type 2 diabetes (T2D) for 3 years, asthma and obstructive sleep apnea was admitted for an aggravation of his dyspnea. Bodyweight was $99 \mathrm{~kg}$, height was $172 \mathrm{~cm}$ and body mass index was $33.5 \mathrm{~kg} / \mathrm{m}^{2}$.

His T2D was treated only with metformin $500 \mathrm{mg}$ twice daily and his latest $\mathrm{Hb} 1 \mathrm{Ac}$ was $6.1 \%$. The patient was not on other regular treatment. In the past 3 weeks, he presented a dry cough that was initially managed with amoxicillin/clavulanic acid and clarithromycin for 5 days. At admission, he presented a normal leucocyte count at $4.3 \mathrm{G} / \mathrm{l}$ with lymphopenia at $0.39 \mathrm{G} / \mathrm{l}$ count and an elevated CRP at $58 \mathrm{mg} / \mathrm{l}$ [2, 3]. Chest CT SCAN showed a bilateral multilobar ground-glass opacification. A nasopharyngeal swab test of SARS-CoV-2 by RT-qPCR was performed the same day in another medical facility and the result was pending.

Twenty-four hours after his admission he presented a worsening of dyspnea, with tachypnea and severe hypoxemia requiring a transfer to the intensive care unit rapidly followed by oro-tracheal intubation for mechanical ventilation support. A vasopressor infusion (norepinephrine) was started. A bronchoalveolar lavage was performed and test of SARS-CoV-2 by RT-qPCR assay was positive. At day 3, he presented a rapidly progressive insulin requirement at a rate of up to 50 units/hour iv of insulin aspart (Table 1). Despite the high insulin doses, he maintained an elevated plasma glucose level at 270 $\mathrm{mg} / \mathrm{dL}$ on average.

His extremely high-dose insulin requirement "resolved" at day 9, and the insulin infusion rate was rapidly reduced, avoiding hypoglycemia (Table 2). He was extubated at day 13 and discharged to an intermediate care unit as a step down approach to pursue a close monitoring and regular respiratory care including continuous positive airway pressure (CPAP), and 2 days later he was transferred to regular hospital room due a positive clinical evolution. His insulin treatment was switched to subcutaneous neutral protamine Hagedorn (NPH) insulin at a total dose of 60 UI per day.

\section{Discussion and conclusions}

This case could reflect a potential severe impact of COVID-19 infection on metabolic homeostasis in a sub-group of patients, in particular diabetic individuals that appear more prone to complications of COVID-19 infection. Yet, the mechanisms behind this remain to be elucidated. No previous report has been made in COVID-19 infection of extremely high-dose insulin requirement. Available data remain limited to assess if COVID-19 infections are more prone to induce metabolic disturbances than SARS-CoV, but previous observations with SARS in 2003 showed that both hyperglycemia and history of diabetes were independent predictors of severe respiratory symptoms and death in SARS-CoV patients, as observed with COVID-19 infection [4-7].

The metabolic response to sepsis encompasses several phenomenons that can contribute to hyperglycemia such as the activation of the hypothalamic-pituitaryadrenal axis, leading to the secretion of cortisol, growth hormone and glucagon resulting in an increased level of glucose. In addition, several mediators of the systemic inflammatory response such as TNF- $\alpha$ or IL-1 may cause hepatic and muscle insulin resistance by disturbing insulin receptor signaling [8]. Interestingly COVID-19 infected patients often present normal or low leucocytes counts and lymphopenia as in our patient [9]. Furthermore, endogenous and exogenous catecholamine used as vasopressors have been reported to increase glucose levels by stimulating glycogenolysis, gluconeogenesis, inhibiting glycogen synthesis and stimulating the release of growth hormone and glucagon [10]. Moreover, a study showed that SARS-CoV may cause diabetes by ACE2-dependent damage of pancreatic islet cells [11]. and similar observation have been made in patients infected with SARS-CoV2, suggesting that this mechanism could be one the factors contributing to metabolism homeostasis disturbance leading to new-onset diabetes and acute hyperglycemia in COVID-19 infection [12].

In the present case, we could hypothesize that COVID-19 infection has led to a high insulin resistance state through several mechanisms including a large release of cytokines named cytokine storm as described in several reports. In addition, catecholamine administration may have exacerbated this state [13]. Furthermore, 


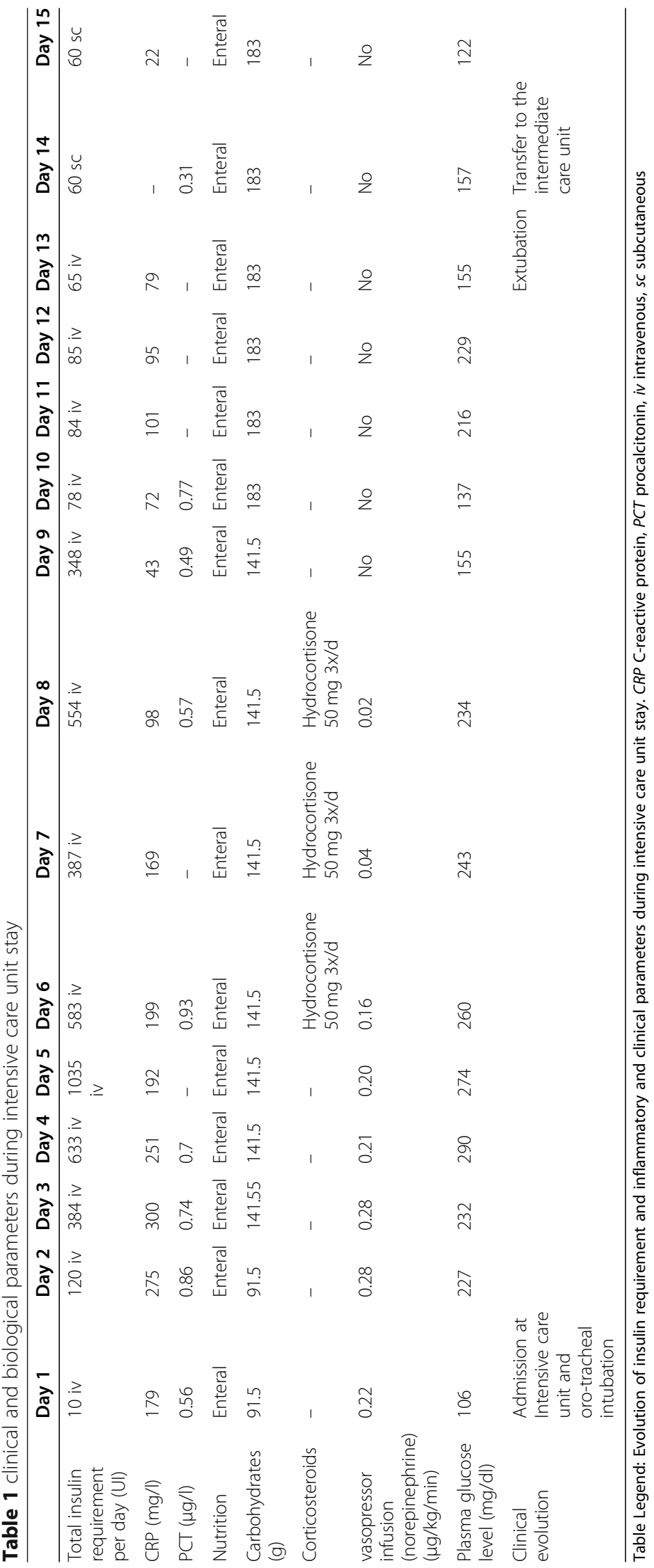


Table 2 Laboratory values at intravenous insulin initiation and withdrawal

\begin{tabular}{|c|c|c|}
\hline Variables & $\begin{array}{l}\text { At intravenous } \\
\text { insulin initiation }\end{array}$ & $\begin{array}{l}\text { At intravenous } \\
\text { insulin withdrawal }\end{array}$ \\
\hline Leukocytes count $\left(10^{-9} / \mathrm{l}\right)$ & 11.4 & 6.0 \\
\hline Lymphocytes count $\left(10^{-9} / 1\right)$ & 0.52 & 1.22 \\
\hline C-reactive protein (mg/l) & 179 & 14 \\
\hline Procalcitonin $(\mu \mathrm{g} / \mathrm{l})$ & 0.56 & N.A. \\
\hline Creatinine $(\mu \mathrm{mol} / \mathrm{l})$ & 80 & 106 \\
\hline Urea $(\mathrm{mmol} / \mathrm{l})$ & 2.6 & 6.4 \\
\hline $\begin{array}{l}\text { Aspartate aminotransferase } \\
\text { (U/liter) }\end{array}$ & 48 & 44 \\
\hline $\begin{array}{l}\text { Alanine aminotransferase } \\
\text { (U/liter) }\end{array}$ & 37 & 25 \\
\hline Bilirubin conjugate $(\mu \mathrm{mol} / \mathrm{l})$ & 11 & 7 \\
\hline Albumin (g/l) & 20 & 36 \\
\hline Potassium (mmol/l) & 3.6 & 3.8 \\
\hline Sodium $(\mathrm{mmol} / \mathrm{l})$ & 135 & 138 \\
\hline Magnesium (mmol/l) & 0.78 & 0.8 \\
\hline Phosphate (mmol/l) & 0.86 & 1.28 \\
\hline Chloride $(\mathrm{mmol} / \mathrm{l})$ & 98 & 102 \\
\hline
\end{tabular}

N.A. non available

T2D is often associated with insulin-resistance due to a low-grade inflammatory state and abnormal plasma oxidative stress that can be exacerbated during an infection episode, leading to intense insulin resistance as presented by our patient [8].

Observational studies are required to better elucidate the impact of COVID-19 infection on glucose metabolism, in particular in diabetic patients, by several approaches such as comparing insulin requirement between patients with COVID-19 infection and patients with other causes of septic shock and ARDS to eventually confirm a potential disproportionate insulin requirement during COVID-19 infection.

\section{Abbreviations}

ARDS: Acute respiratory distress syndrome; CPAP: Continuous positive airway pressure; NPH: Neutral protamine Hagedorn; T2D: Type 2 diabetes

\section{Acknowledgements}

All caregivers who have taken care of the patient.

\section{Authors' contributions}

FRJ and KG wrote the first draft of the manuscript. FRJ, BA, JP and KG edited the manuscript. All authors read and approved the final manuscript.

\section{Funding}

No funding was associated with this work.

\section{Ethics approval and consent to participate}

We have obtained a written informed consent from the patient for this manuscript.

\section{Consent for publication}

Written consent is provided from the participant for the publication of this case study and accompanying data.

\section{Competing interests}

The authors have no competing interests.

\section{Author details}

'Division of Endocrinology, Diabetes, Nutrition and Therapeutic patient education, Geneva University Hospitals, Geneva, Switzerland. ${ }^{2}$ Division of Intensive Care, Geneva University Hospitals, Geneva, Switzerland.

\section{Received: 30 June 2020 Accepted: 28 September 2020}

Published online: 16 October 2020

\section{References}

1. De Block C, Manuel YKB, Van Gaal L, Rogiers P. Intensive insulin therapy in the intensive care unit: assessment by continuous glucose monitoring. Diabetes Care. 2006;29:1750-6.

2. Guan WJ, Ni ZY, Hu Y, Liang WH, Ou CQ, He JX, et al. Clinical characteristics of coronavirus disease 2019 in China. N Engl J Med. 2020;382:1708-20.

3. Bhatraju PK, Ghassemieh BJ, Nichols M, Kim R, Jerome KR, Nalla AK, et al. Covid-19 in critically ill patients in the Seattle region - case series. N Engl J Med. 2020;382:2012-22.

4. Yang JK, Feng Y, Yuan MY, Yuan SY, Fu HJ, Wu BY, et al. Plasma glucose levels and diabetes are independent predictors for mortality and morbidity in patients with SARS. Diabet Med. 2006;23:623-8.

5. Wang S, Ma P, Zhang S, Song S, Wang Z, Ma Y, et al. Fasting blood glucose at admission is an independent predictor for 28-day mortality in patients with COVID-19 without previous diagnosis of diabetes: a multi-Centre retrospective study. Diabetologia. 2020;63(10):2102-11.

6. Mantovani A, Byrne CD, Zheng MH, Targher G. Diabetes as a risk factor for greater COVID-19 severity and in-hospital death: a meta-analysis of observational studies. Nutr Metab Cardiovasc Dis. 2020;30:1236-48.

7. Booth CM, Matukas LM, Tomlinson GA, Rachlis AR, Rose DB, Dwosh HA, et al. Clinical features and short-term outcomes of 144 patients with SARS in the greater Toronto area. JAMA. 2003;289:2801-9.

8. Kolyva AS, Zolota V, Mpatsoulis D, Skroubis G, Solomou EE, Habeos IG, et al. The role of obesity in the immune response during sepsis. Nutr Diabetes. 2014;4:e137

9. Chen N, Zhou M, Dong X, Qu J, Gong F, Han Y, et al. Epidemiological and clinical characteristics of 99 cases of 2019 novel coronavirus pneumonia in Wuhan, China: a descriptive study. Lancet. 2020;395:507-13.

10. Marik PE, Raghavan M. Stress-hyperglycemia, insulin and immunomodulation in sepsis. Intensive Care Med. 2004;30:748-56.

11. Yang JK, Lin SS, Ji XJ, Guo LM. Binding of SARS coronavirus to its receptor damages islets and causes acute diabetes. Acta Diabetol. 2010;47:193-9.

12. Liu F, Long $X$, Zhang B, Zhang W, Chen X, Zhang Z. ACE2 expression in pancreas may cause pancreatic damage after SARS-CoV-2 infection. Clin Gastroenterol Hepatol. 2020;18:2128-30 e2.

13. Mehta P, McAuley DF, Brown M, et al. COVID-19: consider cytokine storm syndromes and immunosuppression. Lancet. 2020;395:1033-4.

\section{Publisher's Note}

Springer Nature remains neutral with regard to jurisdictional claims in published maps and institutional affiliations. 